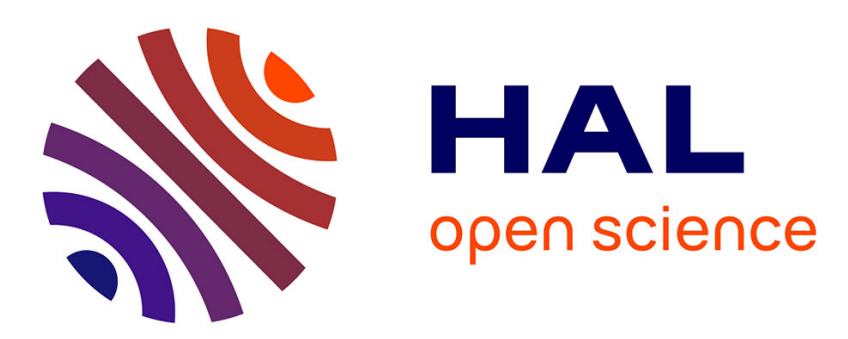

\title{
Multiband Pyramidal Antenna Loaded With a Cutoff Open-Ended Waveguide
}

Sami Hebib, Hervé Aubert, Olivier Pascal, Nelson Fonseca, Lionel Ries, Jean-Marc Lopez

\section{- To cite this version:}

Sami Hebib, Hervé Aubert, Olivier Pascal, Nelson Fonseca, Lionel Ries, et al.. Multiband Pyramidal Antenna Loaded With a Cutoff Open-Ended Waveguide. IEEE Transactions on Antennas and Propagation, 2009, 57 (1), pp. 266 - 270. 10.1109/TAP.2008.2009778 . hal-00432957

\section{HAL Id: hal-00432957 https://hal.science/hal-00432957}

Submitted on 17 Nov 2009

HAL is a multi-disciplinary open access archive for the deposit and dissemination of scientific research documents, whether they are published or not. The documents may come from teaching and research institutions in France or abroad, or from public or private research centers.
L'archive ouverte pluridisciplinaire HAL, est destinée au dépôt et à la diffusion de documents scientifiques de niveau recherche, publiés ou non, émanant des établissements d'enseignement et de recherche français ou étrangers, des laboratoires publics ou privés. 


\title{
Multiband Pyramidal Antenna Loaded With a Cutoff Open-Ended Waveguide
}

Sami Hebib, Hervé Aubert, Olivier Pascal, Nelson J. G. Fonseca, Lionel Ries, and Jean-Marc E. Lopez

\begin{abstract}
An original and flexible pyramidal antenna for satellite or terrestrial application services is presented. The ground plane of the antenna is perforated and loaded with a cutoff open-ended waveguide: this original configuration leads to a good tradeoff between rear radiation and impedance matching. Trap-loads are used to achieve multiband operation while frequency agility may be simply obtained by loading the radiating element by radio-frequency switches. The antenna radiates linearly or circularly polarized electromagnetic fields with quasi-hemispheric radiation patterns at multiple operating frequencies. Several prototypes have been simulated, manufactured, and finally measured. A specific application is given in this paper for a triband GPS/Galileo/MicroSat Telemetry antenna to combine positioning and telemetry applications. The experimental results confirm the good performances observed with the electromagnetic simulations.
\end{abstract}

Index Terms-Cutoff waveguide loading, GPS/Galileo/MicroSAT telemetry services, multiband antenna, pyramidal structure, trap-loads.

\section{INTRODUCTION}

Multiband antennas are often used on satellite systems to reduce the number of on-board and ground antennas. These antennas allow the combination of several applications on the same radiating element. However, the performances of multiband antenna structures are traditionally limited by the arrangement of their constitutive radiating elements especially when agility in terms of frequency allocation is required. Moreover, the multiplicity of frequency bands dedicated to radio-navigation or broadcasting applications reveals the need for multiband antennas having flexible and low cost features, and offering performances equivalent to those obtained from mono-application/single-band antennas. To achieve the aforementioned requirements, flexible high-performance, and circularly polarized multiband antennas are then needed.

Numerous multiband antenna design techniques are discussed in the recent literature. The most common and classic technique consists of combining two or more single band antennas to achieve multiband operation [1], [2]. However, this technique may generate large structures as the number of operating frequency increases. Recently, fractal geometries have been exploited to design multiband antennas [3]-[7]. However, as observed in [8] and [9] standard fractal or prefractal shapes show correlated multiband resonances and consequently, the spacing between the operating frequencies of a fractal antenna is not easy to control in practice. Finally, the multiband feature of radiating elements

Manuscript received April 04, 2008; revised July 02, 2008. Current version published March 04, 2009. This work was supported by the French Space Agency (CNES) by Grant 60168/00.

S. Hebib is with the Laboratoire d'Analyse et d'Architecture des Systèmes, University of Toulouse, Toulouse 31077, France and also with the Laboratoire Micro-ondes et Electromagnétisme, University of Toulouse, 31062 Toulouse, France (e-mail: sami.hebib@gmail.fr).

H. Aubert is with the Laboratoire d'Analyse et d'Architecture des Systèmes, University of Toulouse, Toulouse 31077, France and also with the INPT-ENSEEIHT, 31071 Toulouse, France (e-mail: aubert@enseeiht.fr).

O. Pascal is with the Laboratoire Micro-ondes et Electromagnétisme, University of Toulouse, 31062 Toulouse, France (e-mail: opascal@ cict.fr).

N. J. G. Fonseca, L. Ries, and J.-M. E. Lopez are with the Centre national des études spatiales, 31401 Toulouse, France (e-mail: nelson.fonseca@cnes.fr). 
is also classically obtained by using trap-loads. In dual-frequency design, trap loading has previously been used, e.g., for GPS quadrifilar helix antenna [10], fractal Sierpinski antennas [11], fractal tree antennas [12], and PIFA [13]. Recently, an interesting inverted L triband antenna array has been proposed for GPS applications [14].

A novel topology of circularly or linearly polarized multiband antenna offering frequency flexibility is presented in this paper. The ground plane of the radiating element is perforated and loaded with a cutoff hollow, metallic and open-ended waveguide: it is shown here that this original configuration achieves a good tradeoff between rear radiation and impedance matching. This is the key innovation reported in this paper. The multiband feature of the proposed antenna is achieved by inserting trap-loads along the constitutive radiating monopoles. Moreover a large beamwidth is obtained by using pyramidal structures: such geometry allows bringing closer the feeding ports of the antenna and consequently, obtaining quasi-omnidirectional radiation pattern at the operating frequencies. This is the second important result reported here.

A prototype of the pyramidal multiband antenna loaded with its cutoff and open-ended waveguide is shown in this paper and a specific application is given for a right-handed circular polarization triband GPS/Galileo/MicroSat telemetry antenna to combine positioning and telemetry applications. Preliminary results relative to this application may be found in [15] and [16] but, due to space limitations, these previous reports do not present the design rules and do not discuss the idea of the cutoff open-ended waveguide loading. In this paper, a complete set of electromagnetic simulations and experimental validations are presented and the authors give the design rules of a generic multiband pyramidal antenna loaded with its cutoff waveguide.

\section{ANTENNA DESCRIPTION AND DESIGN RULES}

\section{A. Antenna Geometry}

Consider the antenna shown in Fig. 1(a). It is composed of four radiating elements placed symmetrically around an axis which is perpendicular to a perforated ground plane. We have observed that this perforation allows improving the impedance matching at the input ports of the antenna. The outer radius of the finite-size ground plane influences the antenna gain and axial ratio and it has to be chosen large enough to limit the reflection effect at the outer edge. In Fig. 1(a), the radiating elements are metallic wire monopoles but elements having a triangular shape-like, e.g., bow-tie, Parany or Sierpinski monopoles [Fig. 1(b)] - may advantageously be used for improving the antenna bandwidth [17] (as a drawback, these triangular radiating elements require more trap-loads for multiband features than wire monopoles and occupy more space). The monopoles form a nonzero inclination angle $\theta$ with the ground plane and the excitation points are located at the edge of the perforation. By varying the inclination angle of the radiating elements, the antenna radiation patterns can be shaped to achieve required specifications. The feeding ports are connected to the excita-

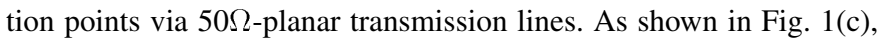
the monopoles are printed on inclined and thin dielectric boards that constitute the side faces of the pyramidal structure. The linear polarization is obtained by feeding two opposite monopoles with equal amplitudes and $180^{\circ}$-phase shift while the circular polarization is obtained when the four monopoles are fed with a progressive $90^{\circ}$-phase shift and equal amplitudes. The sense of the polarization (right-handed or left-handed) is given by the sign of the $90^{\circ}$-phase shift between two successive feeding ports.

\section{B. The Cutoff and Open-Ended Metallic Waveguide}

The presence of the hole in the ground plane [see Fig. 1(a)] generates an undesirable rear electromagnetic radiation. As shown in Fig. 1(c)

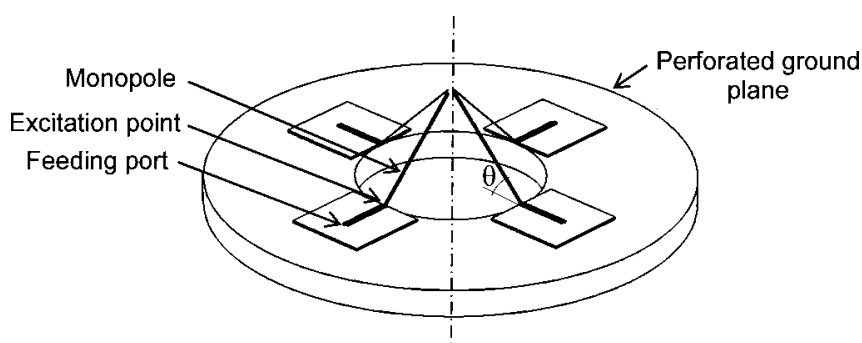

(a)

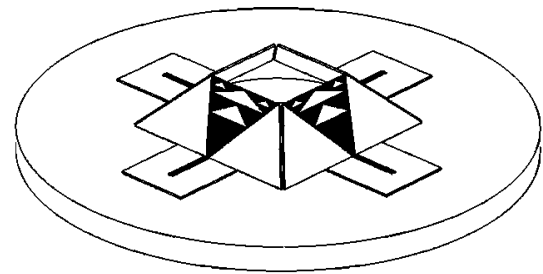

(b)

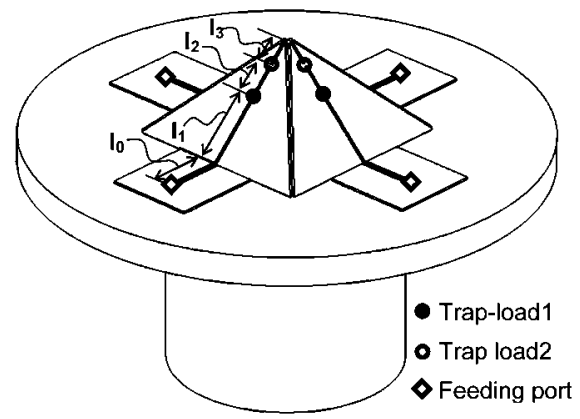

(c)

Fig. 1. The pyramidal antenna with (a) wire and (b) Sierpinski monopoles. (c) The proposed pyramidal multiband antenna structure loaded with a circular and open-ended metallic waveguide.

we propose to reduce this radiation level by loading the ground plane by a cutoff and open-ended metallic waveguide. This waveguide is designed such that no modes are propagating inside of it at the operating frequencies of the antenna. A lossless circular waveguide is considered cutoff when its radius is less than the maximum allowed radius $r_{\max }$ ensuring the evanescence of the first (fundamental) mode. This radius $r_{\max }$ is given by [18]

$$
r_{\max }=\frac{c}{3,413 f_{h}\left(\varepsilon_{r} \mu_{r}\right)^{1 / 2}}
$$

where $c$ is the light celerity in free space, $\varepsilon_{r}$ and $\mu_{r}$ are respectively the relative permittivity and permeability of the medium filling the waveguide and $f_{h}$ designates the highest operating frequency of the antenna loaded with the cutoff circular waveguide.

Since all modes in the waveguide are attenuated, the longer the open-ended waveguide the lower the rear radiation. For illustration purpose, consider a dual-band pyramidal antenna operating at the two following frequencies: 1.197 and $1.575 \mathrm{GHz}$. For simplification, the dielectric substrate is replaced by air and the metallic losses are neglected. From the lowest frequency $(1.197 \mathrm{GHz})$ and the inclination angle of the monopole radiating elements $\left(\theta=45^{\circ}\right)$ the radius of the aperture in the ground plane $r=35 \mathrm{~mm}$ is derived (note that the four feeding ports of the monopole radiating element are taken at the periphery of the circular aperture). Using the highest operating frequency $(1.575 \mathrm{GHz})$ and $(1)$, the maximum radius $r_{\max }$ ensuring a cutoff operation of the circular waveguide is calculated $\left(r_{\max }=55.8 \mathrm{~mm}\right)$. From Zeland IE3D electromagnetic simulator [19], the input reflection 


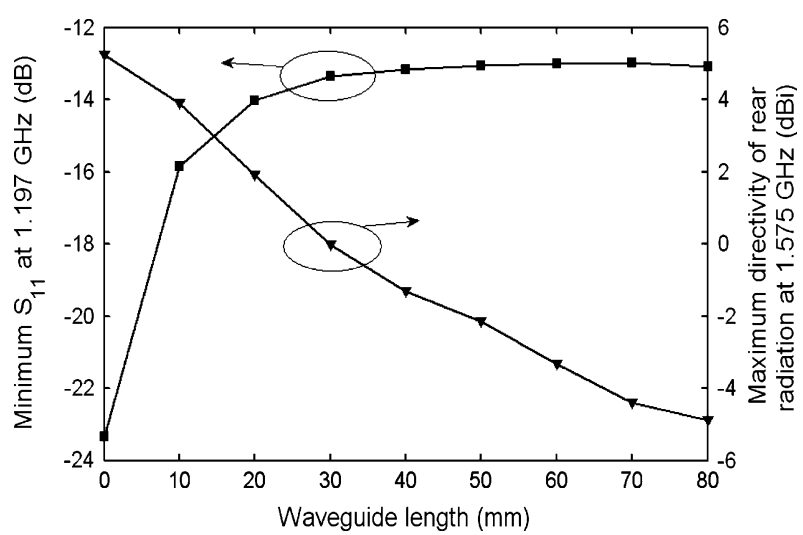

Fig. 2. The minimum $S_{11}$ and the maximum rear radiation directivity versus the length of the cutoff and open-ended metallic waveguide. The highest value of the three minimum reflexion coefficients (one minimum per operating frequency of the triband antenna) is reported.

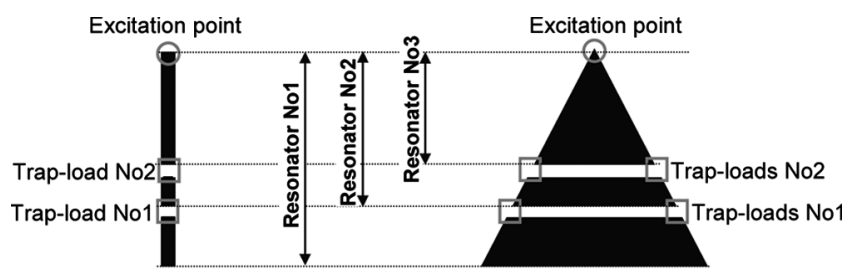

(a)

(b)

Fig. 3. Trap-loads locations along the radiating elements of the triband pyramidal antenna.

and the directivity of the rear radiation presented by the bi-band antenna are computed versus the length of the circular waveguide. The Fig. 2 shows the variation of the maximum directivity of rear radiation at the highest frequency and the minimum $S_{11}$ at the lowest frequency versus the length of the circular waveguide. As expected, the more the open-ended waveguide is long the more the rear radiation is small and the maximum directivity of rear radiation (at elevation angle of $180^{\circ}$ ) is obtained at the highest operating frequency $(1.575 \mathrm{GHz})$. However the more the waveguide is long the more the matching of the antenna is poor and the poorest impedance matching is found at the lowest operating frequency $(1.197 \mathrm{GHz})$. Consequently, varying the length of the cutoff open-ended waveguide allows achieving a good tradeoff between rear radiation and impedance matching at feeding ports.

\section{The Choice and Location of the Trap-Loads}

Trap-loads are inserted on the surface of the radiating elements to achieve a multiband behavior [see Fig. 1(c)]. For a first rapid design, trap-loads are classically considered as perfect short or open circuits depending on the operating frequency. Next, in order to perform more accurate design, trap-loads are modeled by a $L C$ parallel circuit: at its resonant frequency $1 / 2 \pi \sqrt{L C}$ the trap-load is equivalent to an open circuit. The required rejection frequency and bandwidth allow deriving the pertinent values of $L$ and $C$.

As shown in Fig. 3, consider one of the four monopoles of the pyramidal antenna and insert trap-loads on its surface in order to achieve triband monopole at operating frequencies $f_{1}, f_{2}$ and $f_{3}$, with $f_{1}<$ $f_{2}<f_{3}$. Two different types of properly positioned trap-loads are sufficient to obtain such frequencies: trap-load(s) No1 with resonant frequency set at $f_{2}$ and trap-load(s) No2 with resonant frequency set at $f_{3}$.
TABLE I

TECHNICAL REQUIREMENTS FOR THE GPS/GALILEO/MicRosAT TRI-BAND ANTENNA

\begin{tabular}{|c|c|c|c|c|}
\hline & & Band 1 & Band 2 & Band 3 \\
\hline \multicolumn{2}{|c|}{ Bands } & $\begin{array}{c}\text { E5a/L5 and } \\
\text { E5b }\end{array}$ & Extended L1 & TM \\
\hline \multicolumn{2}{|c|}{ Systems } & GPS/Galileo & GPS/Galileo & MicroSat \\
\hline \multicolumn{2}{|c|}{ Center frequency } & $1.197 \mathrm{GHz}$ & $1.575 \mathrm{GHz}$ & $2.245 \mathrm{GHz}$ \\
\hline \multicolumn{2}{|c|}{$\begin{array}{c}\text { Target bandwidth } \\
\left(\left|\mathrm{S}_{11}\right|<-10 \mathrm{~dB}\right)\end{array}$} & $50 \mathrm{MHz}$ & $32 \mathrm{MHz}$ & $90 \mathrm{MHz}$ \\
\hline \multicolumn{2}{|c|}{ Polarization } & \multicolumn{3}{|c|}{ Right-Handed Circular } \\
\hline \multirow{5}{*}{$\begin{array}{l}\text { Minimum } \\
\text { directivity }\end{array}$} & $\theta=0^{\circ}$ & \multicolumn{2}{|c|}{$>2 \mathrm{dBi}$} & $>1 \mathrm{dBi}$ \\
\hline & $0^{\circ}<|\theta|<50^{\circ}$ & \multicolumn{2}{|c|}{$>-5 \mathrm{dBi}$} & $>1 \mathrm{dBi}$ \\
\hline & $50^{\circ}<|\theta|<60^{\circ}$ & \multicolumn{2}{|c|}{$>-5 \mathrm{dBi}$} & $>2 \mathrm{dBi}$ \\
\hline & $60^{\circ}<|\theta|<70^{\circ}$ & \multicolumn{2}{|c|}{$>-5 \mathrm{dBi}$} & $>-1 \mathrm{dBi}$ \\
\hline & $70^{\circ}<|\theta|<80^{\circ}$ & \multicolumn{2}{|c|}{$>-5 \mathrm{dBi}$} & $>-5 \mathrm{dBi}$ \\
\hline
\end{tabular}

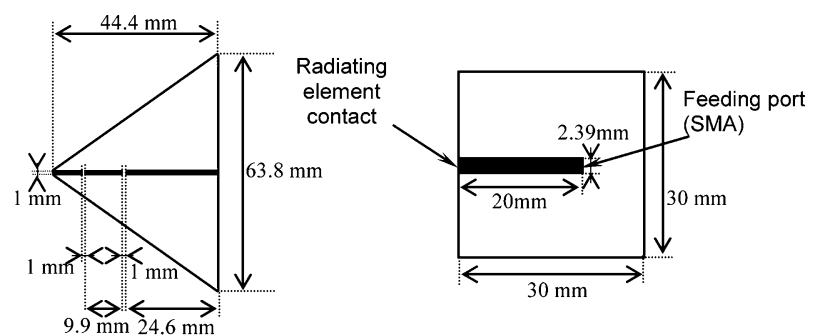

(a)

(b)
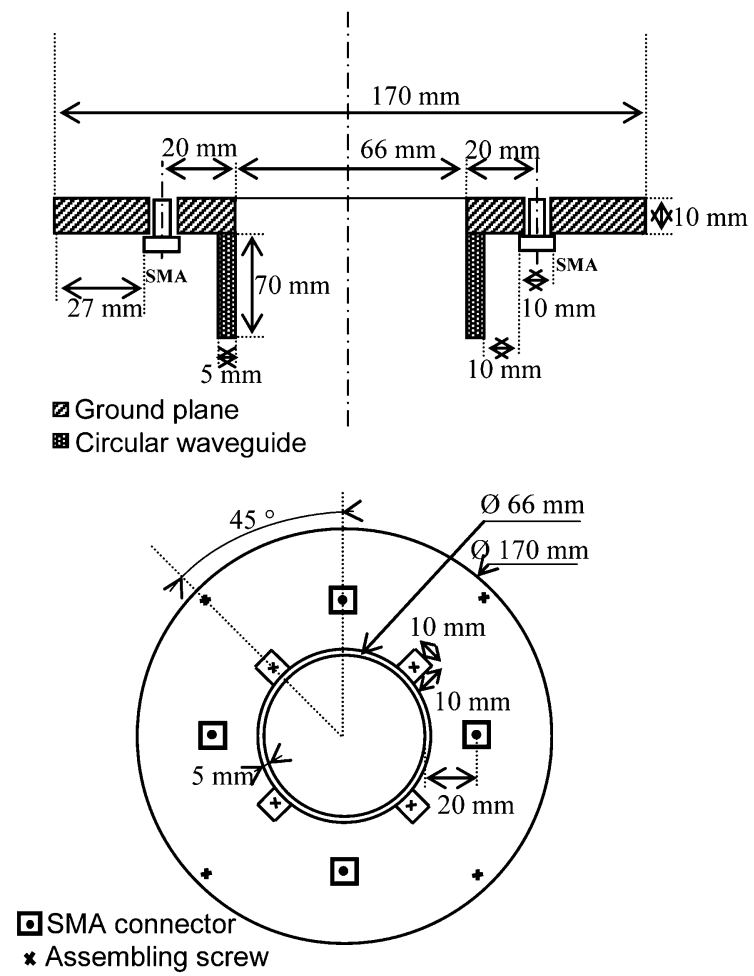

(c)

Fig. 4. Dimensions of: (a) The radiating elements. (b) The $50 \Omega$-microstrip lines. (c) The ground plane, its perforation, and the mechanical dimensions.

The chip components (capacitors and inductors) are very suitable for the design of trap-loads due to their compactness, the easy integration and their reduced effect on the antenna radiation patterns. However, the matching and the bandwidth of the antenna are highly dependent on the performances of these chip components. Their scattering parameters (S-parameters) are usually given by the manufacturer but, in order to perform an accurate design, the measurement of the S-parameters is needed in practice before mounting trap-loads on the radiating element. 


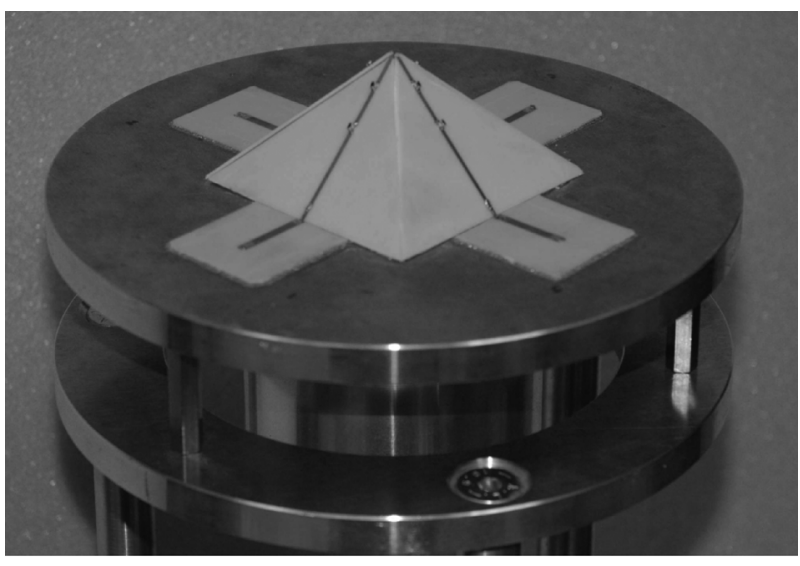

(a)

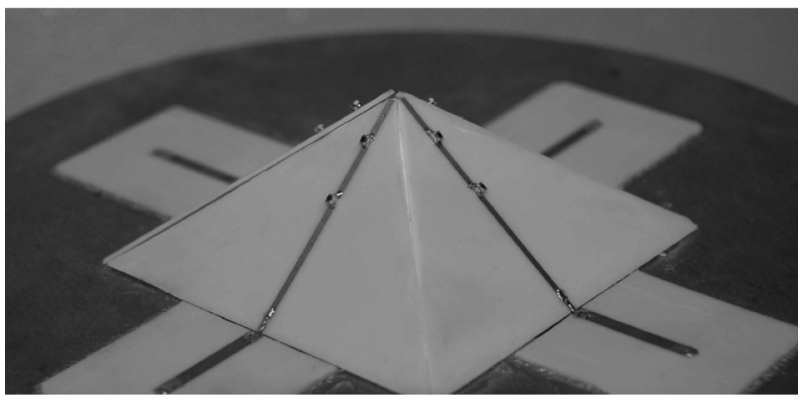

(b)

Fig. 5. The fabricated pyramidal triband antenna: (a) The antenna with the maintaining support. (b) Zoom on the pyramidal structure.

\section{TRIBAND ANTENNA FOR GPS/GALILEO/Microsat TELEMETRY SERVICES}

This application concerns the design, manufacturing and measurement of a triband antenna for telemetry application. The frequency plan and the technical requirements are given in Table I and the corresponding triband antenna is shown in Fig. 1(c).

The design of the antenna has been performed by using Zeland IE3D and the fine electromagnetic simulations are provided by means of a finite-difference time-domain (FDTD) method using CST Microwave Studio software [20]. The four radiating elements that constitute the antenna are metallic strips of width $1 \mathrm{~mm}$ printed on a NELTEC relatively low-permittivity substrate $\left(\varepsilon_{r}=2.08\right.$ and thickness of $\left.762 \mu \mathrm{m}\right)$. The lengths $l_{1}, l_{2}$, and $l_{3}$ of radiating elements are 24.6, 9.9, and $7.9 \mathrm{~mm}$, respectively. The same substrate is used for the design of the $50 \Omega$-microstrip transmission lines that place the four feeding ports at $20 \mathrm{~mm}$ from the edge of the ground plane hole. The dimensions of the building blocks of the antenna (in particular the microstrip transmission line, the radiating strips and the location of the trap-loads) are given in Fig. 4. The outer radius of the ground plane is $85 \mathrm{~mm}$. Minor safety margins are added to the radius of the ground plane hole in order to avoid any possible manufacturing defects. The cutoff open-ended metallic waveguide used for controlling the rear radiation and impedance matching has an inner radius equal to that of the ground plane hole $(33 \mathrm{~mm})$ and a length of $70 \mathrm{~mm}$. This length is adjusted for minimizing the rear electromagnetic radiation. Four SMA connectors are used to feed the antenna. The positions of the assembling screws as well as the widths of the rings supporting the antenna were taken such that the overall performances of the antenna are not much degraded. A pyramidal inclination of $\theta=45^{\circ}$ is chosen as a good tradeoff between the expected radial and axial radiation performances. MuRata chip capacitors (C)
TABLE II

THE SELECTED TRAP-LOADS COMPONENTS FOR THE GPS/GALILEO/MicROSAT TRIBAND ANTENNA

\begin{tabular}{|c|c|c|c|}
\hline & Component & Value & Reference number \\
\hline $\begin{array}{c}\text { Trap-load } \\
\text { components for } \\
\text { TM MicroSat band }\end{array}$ & Inductor & $4.3 \mathrm{nH}$ & LQW18AN4N3C00 \\
\cline { 2 - 4 } & Capacitor & $1.2 \mathrm{pF}$ & GQM1885C2A1R2CB01 \\
\hline $\begin{array}{c}\text { Trap-load } \\
\text { components for L1 } \\
\text { GPS/Galileo band }\end{array}$ & Inductor & $12.0 \mathrm{nH}$ & LQW18AN12NG10 \\
\cline { 2 - 4 } & Capacitor & $0.75 \mathrm{pF}$ & GQM1885C2AR75CB01 \\
\hline
\end{tabular}

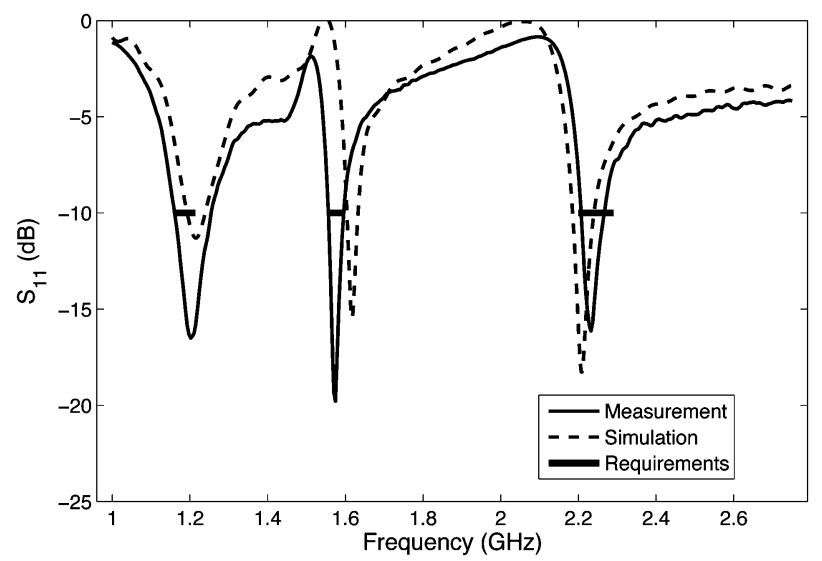

Fig. 6. $S_{11}$ versus frequency of the pyramidal GPS/GALILEO/MicroSat triband antenna.

and inductors (L) are chosen here for their compactness (EIA size 603: $1.6 \mathrm{~mm} \times 0.8 \mathrm{~mm}$ ) and reliability. These chip components are mounted on small boards and the S-parameters of the corresponding trap-loads are determined experimentally. From these measurements, the choice of pertinent couples (L,C) is performed (see Table II). The picture of the final pyramidal triband antenna with its trap-loads is given in Fig. 5.

The measured $S_{11}$ of the triband antenna is depicted in Fig. 6, and compared to simulation results. The measured central frequencies are: 1.204, 1.572, and $2.228 \mathrm{GHz}$. The corresponding bandwidths (for $\left|S_{11}\right|<-10 \mathrm{~dB}$ ) are respectively 96,43 , and $57 \mathrm{MHz}$.

Fig. 7 displays the simulated and measured Right Handed (RH-) and Left Handed (LH-) Circular Polarization (CP) directivity patterns of the antenna at the three operating frequencies. The measured radiation patterns are in good agreement with the nominal required specifications in the first band (E5a,b and L5 GPS/Galileo bands). In the intermediate (Extended L1 GPS/Galileo bands) and highest frequency bands (TM MicroSat), the patterns are slightly out of the technical requirements in some radiating directions. This can be improved by adjusting the inclination angle of the radiating wires. As it can be observed from Fig. 7, the radiation patterns of the antenna are quasi-hemispheric, allowing a maximum reception of signals from the satellites in sight (visibility). The cross polarization obtained by simulation is lower than $-10 \mathrm{~dB}$ in the half space of interest, thus, ensuring a purity of polarization compatible with a good antenna operation.

\section{CONCLUSION}

A novel multiband antenna based on pyramidal structures loaded with cutoff and open-ended waveguide has been presented and tested experimentally. The waveguide loading allows a good tradeoff between rear radiation and impedance matching. The measurement results confirm the very good performances derived from the electromagnetic simulations. 


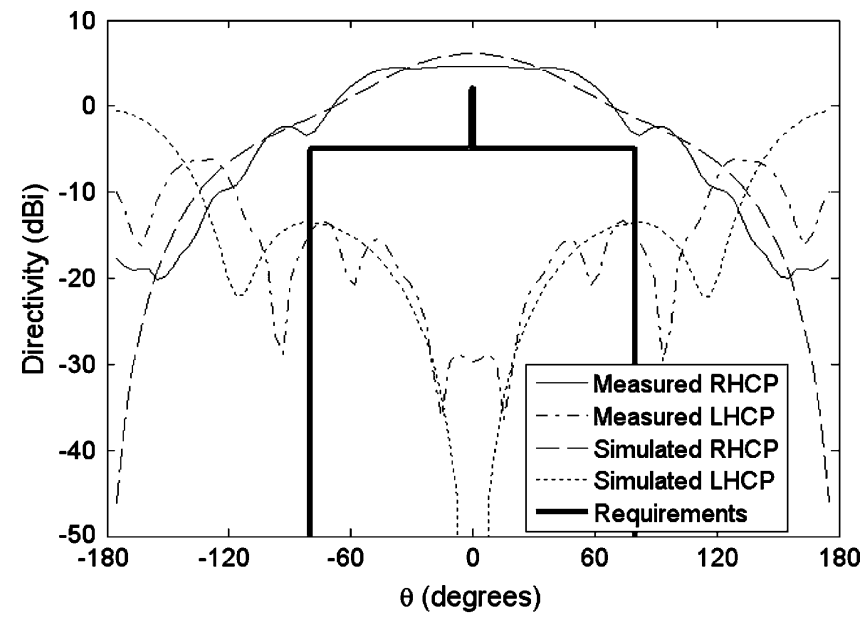

(a)

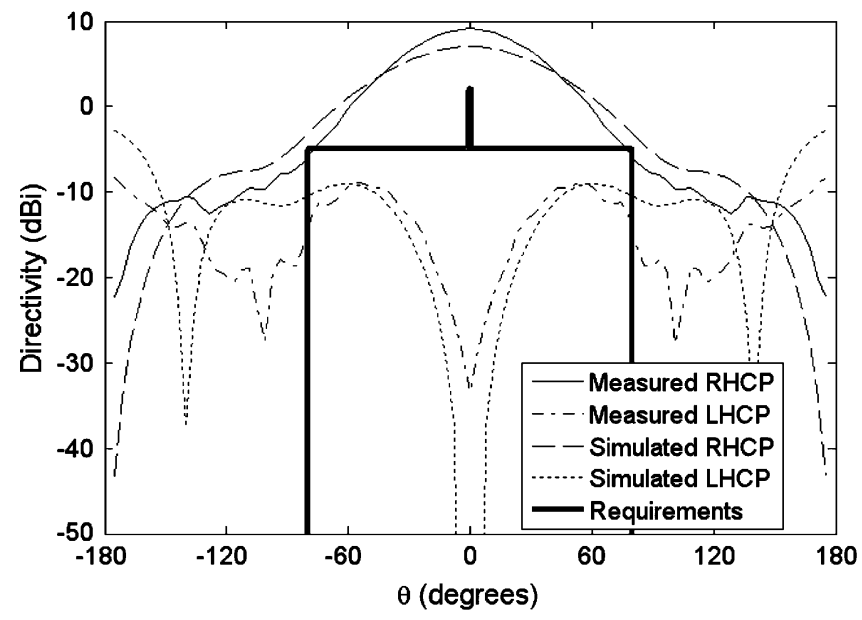

(b)

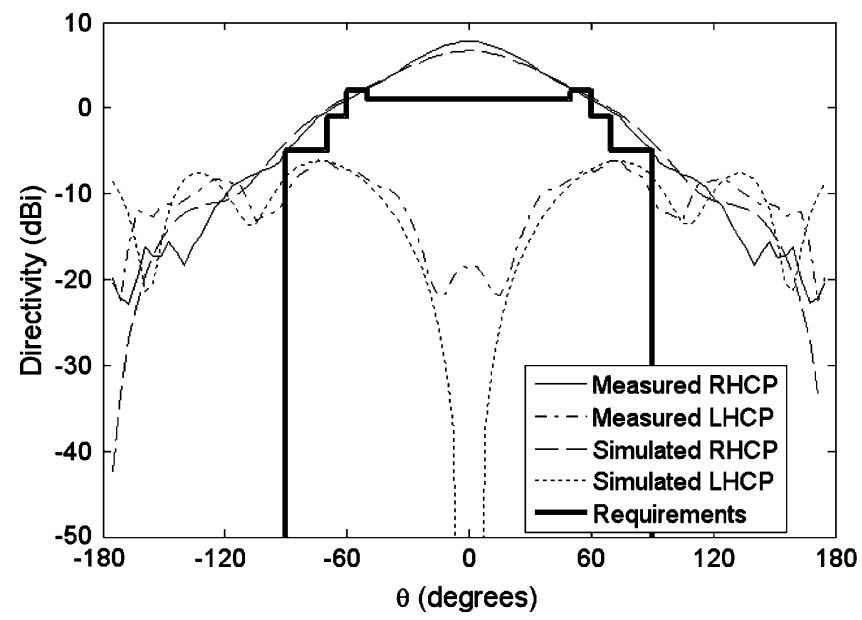

(c)

Fig. 7. Radiation patterns of the triband antenna at: (a) $1.2 \mathrm{GHz}$. (b) $1.57 \mathrm{GHz}$. (c) $2.23 \mathrm{GHz}$.

By the simple structure feature of the antenna proposed here, several possibilities can be exploited. In other words, the various possible adjustments allowed by this antenna (inclination angle, geometry of the metallic radiating elements and ground plane, trap-loads and/or switches) contribute to a multiapplication use. The proposed multiband antenna is easy to design and is flexible. It is a good candidate for other satellite or terrestrial multiband applications.

\section{ACKNOWLEDGMENT}

The authors would like to thank C. Mangenot from ESA/ESTEC for helpful discussions. The authors would also like to acknowledge D. Kitenge, Murata Electronique S.A.S., France, for offering the chip components.

\section{REFERENCES}

[1] Y.-S. Liu, J.-S. Sun, R.-H. Lu, and Y.-J. Lee, "New multiband printed meander antenna for wireless applications," Microw. Opt. Technol. Lett., vol. 47, no. 6, pp. 539-543, Dec. 2005.

[2] P. Eratuuli, P. Haapala, and P. Vainikainen, "Dual frequency wire antennas," Electron. Lett., vol. 32, no. 12, pp. 1051-1052, Jun. 1996.

[3] C. Puente, J. Romeu, R. Pous, and A. Cardama, "On the behavior of the Sierpinski multiband fractal antenna," IEEE Trans. Antennas Propag., vol. 46, no. 4, pp. 517-524, Apr. 1998.

[4] C. Puente, J. Romeu, R. Bartoleme, and R. Pous, "Perturbation of the Sierpinski antenna to allocate operating bands," Electron. Lett., vol. 32, pp. 2186-2188, Nov. 1996.

[5] J. Romeu and J. Soler, "Generalized Sierpinski fractal multiband antenna," IEEE Trans. Antennas Propag., vol. 49, no. 8, pp. 1237-1239, Aug. 2001

[6] K.-C. Hwang, "A modified Sierpinski fractal antenna for multiband application," IEEE Antennas Wireless Propag. Lett., vol. 6, pp. 357-360, 2007.

[7] W. Tang and P. F. Wahid, "Hexagonal fractal multiband antenna," IEEE Antennas Wireless Propag. Lett., vol. 3, no. 1, pp. 111-112, 2004.

[8] S. R. Best, "On the radiation pattern characteristics of the Sierpinski and modified Parany gasket antennas," IEEE Antennas Wireless Propag. Lett., vol. 1, no. 1, pp. 39-42, 2002.

[9] S. R. Best, "On the significance of self-similar fractal geometry in determining the multiband behaviour of the Sierpinski gasket antenna," IEEE Antennas Wireless Propag. Lett., vol. 1, no. 1, pp. 22-25, 2002.

[10] D. Lamensdorf and M. A. Smolinski, "Dual-band quadrifilar helix antenna," in Proc. IEEE AP-S Int. Symp. USNC/URSI National Radio Sci. Meet., San Antonio, TX, Jun. 16-21, 2002, vol. 3, pp. 488-491.

[11] J. P. Gianvittorio and Y. Rahmat-Samii, "Fractal Yagi antennas: Design, simulation, and fabrication," Microw. Opt. Technol. Lett., vol. 41, no. 5, pp. 375-380, Jun. 2004.

[12] J. S. Petko and D. H. Werner, "Miniature reconfigurable three-dimensional fractal tree antennas," IEEE Trans. Antennas Propag., vol. 52, no. 8, pp. 1945-1956, Aug. 2004.

[13] G. K. H. Lui and R. D. Murch, "Compact dual-frequency PIFA designs using LC resonators," IEEE Trans. Antennas Propag., vol. 49, no. 7, pp. 1016-1019, Jul. 2001.

[14] B. R. Rao, M. A. Smolinski, C. C. Quach, and E. N. Rosario, "Tripleband GPS trap-loaded inverted L antenna array," Microw. Opt. Technol. Lett., vol. 38, no. 1, pp. 35-37, Jul. 2003.

[15] S. Hebib, H. Aubert, O. Pascal, N. Fonseca, L. Ries, and J. M. Lopez, "Pyramidal multiband antennas for GPS/Galileo/MicroSat application," in Proc. IEEE AP-S Int. Symp., Honolulu, HI, Jun. 2007, pp. 2041-2044.

[16] S. Hebib, H. Aubert, O. Pascal, N. Fonseca, L. Ries, and J. M. Lopez, "Trap-loaded pyramidal triband antenna for satellite applications," in Proc. IEEE AP-S Int. Symp., San Diego, Jul. 2008.

[17] Y.-D. Lin and S.-N. Tsai, "Analysis and design of broadside-coupled striplines-fed bow-tie antennas," IEEE Trans. Antennas Propag., vol. 46, no. 3, pp. 459-460, Mar. 1998.

[18] R. E. Collin, Field Theory of Guided Waves, 2nd ed. New York: IEEE, 1991.

[19] Zeland IE3D 12.3. Fremont, CA, Zeland Software, Inc..

[20] CST Microwave Studio, ver. 2006B. Darmstadt, Germany, CST. 